\title{
Effects of the LASIK flap thickness on corneal biomechanical behavior: a finite element analysis
}

\author{
Lihua Fang ${ }^{1 *}$ (D, Yan Wang ${ }^{2}$, Ruizhi Yang ${ }^{1}$, Sijing Deng ${ }^{1}$, Jiahao Deng ${ }^{1}$ and Linsun Wan ${ }^{1}$
}

\begin{abstract}
Background: It is well known that the biomechanical properties change after LASIK refractive surgery. One reason is the impact of flap creation on the residual stroma. The results have revealed that the change is closely related with the flap thickness in several studies. However, the quantitative relationships between the distributions of displacement and stress on the corneal surface and flap thickness have not been studied. The aim of the study was to quantify evaluate the biomechanical change caused by the LASIK flap.
\end{abstract}

Methods: By building a finite element model of the cornea, the displacement, the stress and the strain on the corneal surface were analyzed.

Results: The results showed that the corneal flap could obviously cause the deformation of the anterior corneal surface. For example, the displacement of the corneal vertex achieved $15 \mu \mathrm{m}$ more than that without corneal flap, when the thickness of corneal flap was $120 \mu \mathrm{m}$ thick. This displacement was enough to cause the change of aberrations in the human eyes. In the central part of the cornea, the stress on the anterior corneal surface increased with flap thickness. But the change in the stress on the posterior corneal surface was significantly less than that on the anterior surface. In addition, the stress in the central part of the anterior corneal surface increased significantly as the intra-ocular pressure (IOP) increase. Furthermore the increase of IOP had a clearly less effect on stress distribution at the edge of the cornea. Distributions of strain on the corneal surface were similar to those of stress.

Conclusions: The changes in the biomechanical properties of cornea after refractive surgery should not be ignored.

Keywords: Biomechanical change, Finite element model, LASIK flap, Displacement, Stress

\section{Background}

Modern excimer laser refractive surgery attempts to correct refractive errors by altering the shape of the front surface of the cornea [1]. Despite the great potential of refractive surgery, there are still many complications associated with it, such as post-LASIK corneal ectasia [2]. In fact, the surgical outcomes are not always as expected. Several risk factors have been identified for these

\footnotetext{
* Correspondence: fanglh71@126.com

This is to certify that:The article has not been presented in a meeting. All the authors have no financial or proprietary interest in a product, method, or material described herein.

${ }^{1}$ Key Laboratory of National Engineering Laboratory for Nondestructive Testing and Optoelectric Sensing Technology and Application (Ministry of Education), Nanchang Hangkong University, Add: No 696. Fenghenan Rd, Donghu District, Nanchang city, Jiangxi Province, 330063, China Full list of author information is available at the end of the article
}

outcomes, such as a large preoperative myopic refractive error, a thin residual stromal bed, or other corneal topographic abnormalities [3]. In fact, the impact of flap creation on the residual stroma most likely plays a critical role in induced ocular higher-order aberrations [4]. Biomechanical effects of the residual stroma after refractive surgery might also play a role in changes in the corneal curvature that do not represent a development of ectasia but that actually affect refractive outcome [5].

A finite element simulation of corneal biomechanical behavior can predict ophthalmic surgery and the material parameters of the cornea [6, 7]. Recent developments in wavefront analysis $[8,9]$, corneal material characterization, and topographic mapping offer extremely valuable information for numerical modeling. The finite element simulation 
is one of the cornerstones of the biomechanical approach to improving visual outcomes after surgery [10]; therefore, the finite element model (FEM) has been used to simulate the changes in mechanical properties caused by the LASIK flap.

Theoretical simulation plays an important role in improving clinical practice. For example, a numerical model can be adopted in clinical practice to plan and optimize refractive surgeries $[11,12]$. FEM can be a useful tool for providing insight into the effects of such alterations of material properties of the geometry and optical performance of the human eye. Here, we are attempted to assess the biomechanical changes caused by the LASIK flap in FEM.

The purposes of this study were to (1) analyze the corneal biomechanical properties as a response to changes in flap thickness; (2) investigate the behavior of the cornea under different loading states and improve the predictions of the mechanical response to refractive surgery, and (3) assess the distribution of stress and strain on the corneal surface, especially the nonuniform distribution of stress.

\section{Methods}

\section{Geometric model of the cornea}

The cornea consists of the following five distinct cell layers: outer epithelium; Bowman's membranes; central stroma; Descemet's membranes, and inner endothelium, where the stroma is an important part of the cornea. At the micro level, the stroma forms $\sim 90 \%$ of the corneal thickness and is composed of thin collagen fibrils, corneal cells, and extracellular viscous matter. In general, the anterior and posterior surfaces of the normal human cornea are ellipsoidal. In this study, human cornea data, such as mathematical models of the anterior and posterior surfaces, are as follows:

Anterior corneal surface

$$
\frac{x^{2}}{R_{x}}+\frac{y^{2}}{R_{y}}+\frac{\left(z-R_{z}\right)^{2}}{R_{z}}=1,
$$

In the equation, $R_{x}, R_{y}$ and $R_{z}$ are the half-shaft of horizontal, vertical and longitudinal direction respectively on anterior corneal surface, which is about 7 to 8 $\mathrm{mm}$.

Posterior corneal surface

$$
\frac{x^{2}}{R_{x}}+\frac{y^{2}}{R_{y}}+\frac{\left(z-R_{z}-d\right)^{2}}{R_{z}}=1
$$

In the equation, $R_{x}, R_{y}$ and $R_{z}$ are the half-shaft of horizontal, vertical and longitudinal direction respectively on posterior corneal surface, which is about 6.7 to $7.6 \mathrm{~mm}$. The $d$ represents the central thinnest corneal thickness (CCT).

\section{Material properties}

The cornea is somewhat incompressible tissue that shows nonlinear stress-strain characteristics [13]. In addition, the cornea is modeled as isotropic material, and the formula for hyperelastic material has been used to simulate its elastic properties; therefore, the behavior of the cornea material can be presumed to follow the Ogden Hyperelastic Material model. The strain energy potential can be expressed using the following equation [14]:

$$
\begin{aligned}
\mathrm{W}= & \sum_{i=1}^{N} \frac{\mu_{i}}{\alpha_{i}}\left(\bar{\lambda}_{1}^{\alpha_{i}}+\bar{\lambda}_{2}^{\alpha_{i}}+\bar{\lambda}_{3}^{\alpha_{i}}-3\right) \\
& +\sum_{\mathrm{k}=1}^{N} \frac{1}{d_{k}}(J-1)^{2 k}
\end{aligned}
$$

Where W conveys the strain energy potential, $\bar{\lambda}_{p}$ represents deviatoric principal stretches defined as $\bar{\lambda}_{p}=J^{-\frac{1}{3}} \lambda_{p}$ and $\lambda_{p}$ depicts the principal stretches of the left CauchyGreen tensor, and $J$ represents the determinant of the elastic deformation gradient.

$$
N, \mu_{p}, \alpha_{p} \text { and } d_{p}=\text { material constants. }
$$

The initial shear modulus is defined as

$$
\mu=\frac{1}{2} \sum_{i=1}^{N} \alpha_{i} \mu_{i},
$$

And the initial bulk modulus is defined as

$$
K=\frac{2}{d_{1}}
$$

For the purposes of the current study, the experimentally derived stress-versus-strain data were fit to the above material model. The parameters $\mu_{1}$ and $\alpha_{1}$ are hyperelastic constants obtained from fitting the experimental stress-versus-strain data, with the values of $0.60415 \mathrm{Mpa}$ and 16.54 , respectively [15]. The Poisson ratio values of the human cornea ranges from 0.42 to 0.5 , which denotes that the cornea tissue exhibits a nearly incompressible behavior [16].

\section{The finite element model of the cornea}

In light of the shape and characteristics of the cornea, the generation of hex dominant computational fluid dynamics (CFD) mesh was selected. The central thickness $d$ of the cornea was $\sim 0.55 \mathrm{~mm}$ [17]. In order to ensure both computational efficiency and simulation accuracy, when mesh density failed to achieve a significant change in nodal displacement we considered the model sufficiently resolved, the size of meshes was selected to be $0.20-0.30 \mathrm{~mm}$. The "free orientation unit" was 
selected to more rationally and conveniently generate a satisfactory mesh. The corneal model comprised 5708 units and 9753 nodes after mesh generation, as shown in Fig. 1. For different corneal flap thicknesses, there were slight differences in the number of units and nodes included in the corneal model.

The corneal boundary and other tissues, such as the sclera, were restrained and firmly fixed by the surrounding biological tissues, including the ciliary processes and iris, as a shell of which the bottom edges are clamped; therefore, the restrained bottom interface of the cornea could be considered to be a clamped boundary.

\section{Simulation of corneal flaps}

The corneal flap refers to a thin flap of corneal tissue that is cut during refractive surgery. In our study, the diameter of the corneal flap was $8.1 \mathrm{~mm}$, and the thickness of the corneal flap was presumed to be 90, 120, 150, 180, 210, and $240 \mu \mathrm{m}$, respectively (Fig. 2).

\section{Corneal shape change and stress distribution}

The changes in corneal shape refer mainly to the displacement of the corneal surface. The refractive power of a normal eye is mainly from the anterior corneal surface; therefore, only the displacement of the anterior corneal surface was studied here from two perspectives. First, we explored the relationship between displacement of the anterior corneal surface and the thickness of the corneal flap. The displacement of the anterior corneal surface referred to the difference between the displacement of the anterior corneal surface with and without the corneal flap under the same IOP. Second, we studied the relationship between displacement of the anterior corneal surface and IOP. The displacement of the anterior corneal surface was the difference between the displacements of the anterior corneal surface under different IOPs with the same corneal flap thickness. The stress distribution on the corneal surface was also studied from two aspects. First, the influence of changes in IOP on stress distribution on the corneal surface was assessed (i.e., the stress distribution on the anterior and posterior corneal surfaces under the same corneal flap thickness). Second, the influence of the thickness of the corneal flap on the stress distribution on the corneal surface was studied (i.e., stress distribution on the anterior and posterior corneal surfaces under the same IOP).

\section{Results}

Influence of the thickness of corneal flap on the displacement of the anterior corneal surface

Figure 3 showed the relationship between the corneal vertex displacement and corneal flap thickness. To present more comprehensive corneal mechanical properties, the range of IOP was from $15 \mathrm{mmHg}$ to 49 mmHg. In addition, we observed that displacement of the anterior corneal surface showed rotational symmetry; therefore, we studied the relationship between displacement of the anterior corneal surface along the $\mathrm{Y}$-axis and the thickness of the corneal flap. In the study, IOP was constant at $17 \mathrm{mmHg}$, and the thickness of the corneal flap was set to $90,120,150,180$, and $210 \mu \mathrm{m}$, respectively.

As shown in Fig. 3(a), under the same IOP, there was an approximate linear relationship between corneal vertex displacement and IOP. For example, the change in corneal vertex displacement when the corneal flap was $150 \mu \mathrm{m}$ thick was more significant than when the corneal flap was $120 \mu \mathrm{m}$ thick. Similarly, the change in corneal vertex displacement when the flap was $240 \mu \mathrm{m}$ thick was more significant than when the flap was $210 \mu \mathrm{m}$ thick. As shown in Fig. 3(b), there was maximum displacement on corneal vertex, but the displacement of the flap edge was very small. The displacement of the anterior corneal surface showed a similar rotational symmetry. It was obvious that production of corneal flap could result in deformation of the anterior corneal surface. When the flap thickness was $240 \mu \mathrm{m}$, corneal vertex displacement was $30 \mu \mathrm{m}$ larger than that when there was no corneal flap, which is enough to cause corneal aberrations.

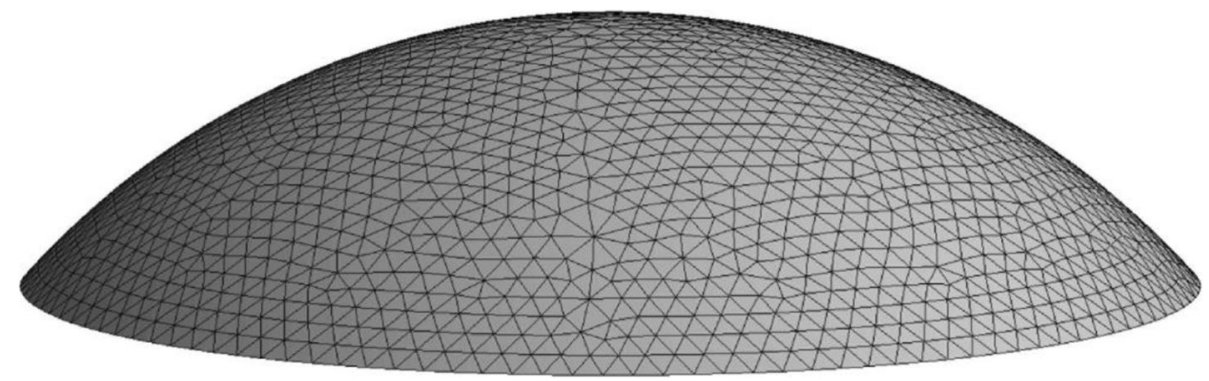

Fig. 1 Finite element mesh of the original cornea 


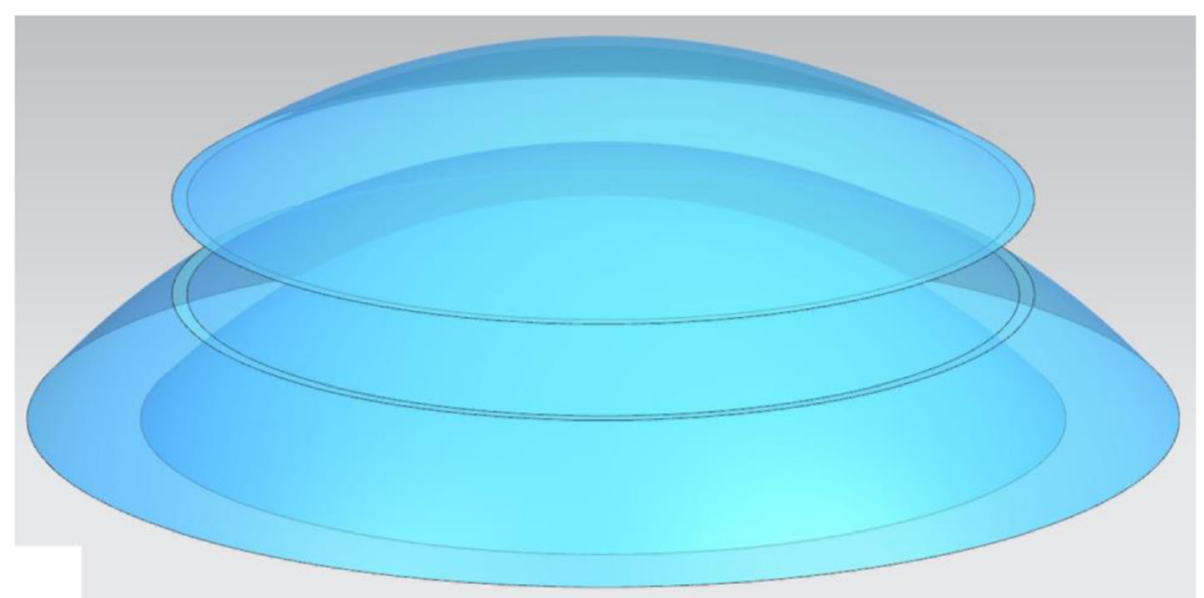

Fig. 2 Corneal flap $8.1 \mathrm{~mm}$ in diameter and $120 \mu \mathrm{m}$ thick

\section{Effect of IOP on the displacement of the anterior corneal surface}

Figure 4 showed the relationship between displacement of the corneal vertex and IOP. To show more comprehensive mechanical properties of the cornea, the maximum IOP was up to $49 \mathrm{mmHg}$, and the maximum flap thickness was set to $240 \mu \mathrm{m}$. The relationship between the displacement of the anterior corneal surface along the $\mathrm{Y}$-axis and IOP was studied. IOP was assumed to be 15-49 $\mathrm{mmHg}$ and flap thickness was assumed constant at $120 \mu \mathrm{m}$.

As shown in Fig. 4(a), there was a significant linear relationship between corneal vertex displacement and IOP. In other words, when IOP was less than $49 \mathrm{mmHg}$, the biomechanical behavior of the cornea showed a linear relationship. As shown in Fig. 4(b), when the flap thickness was constant, the displacement of the anterior corneal surface increased linearly with IOP.

\section{Influence of the thickness of corneal flap on the stress on the corneal surface}

Figure 5 showed the two-dimensional distribution of stress on the anterior corneal surface.

As shown in Fig. 5, stress distribution on the corneal surface had a nearly, but not completely, rotational symmetry. In fact, the cover of eyelid also affected stress distribution. On the other hand, it could be seen from the skeleton map along the $\mathrm{X}$ - and $\mathrm{Y}$-axes that stress distribution was basically consistent; therefore, in subsequent analyses, only the distribution of stress and strain along the Y-axis was analyzed.

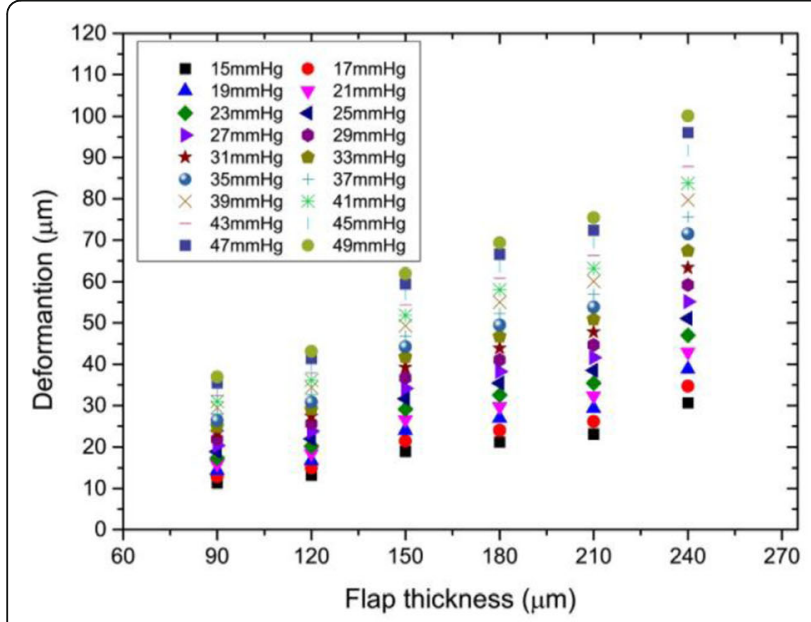

(a)

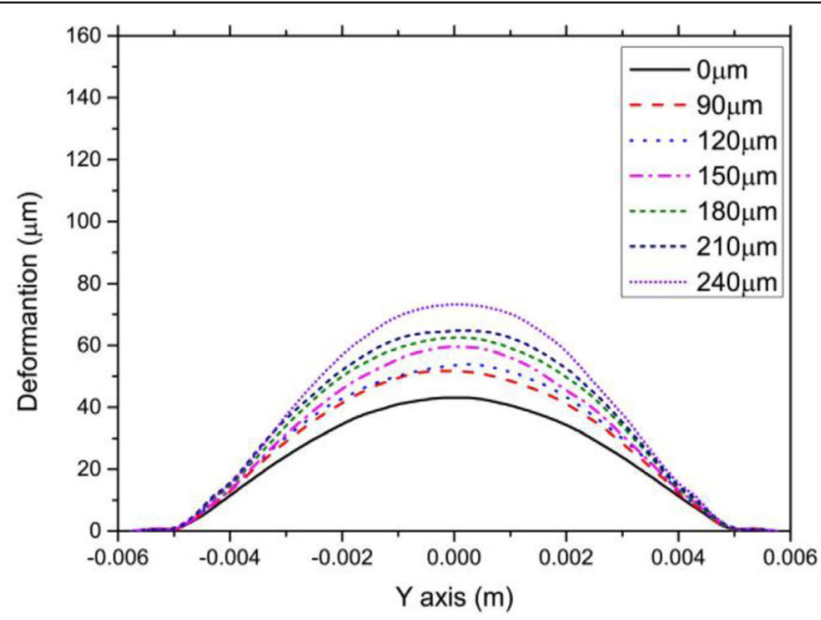

(b)

Fig. 3 a Relationship between corneal vertex displacement and corneal flap thickness. Intraocular pressure ranged from 15 to $49 \mathrm{mmHg}$. b Relationship between the anterior corneal surface displacement along the Y-axis and corneal flap thickness. The corneal flap thickness was assumed to be $90,120,150,180,210$, and $240 \mu \mathrm{m}$, respectively. The unit of corneal vertex displacement was $\mu \mathrm{m}$ 


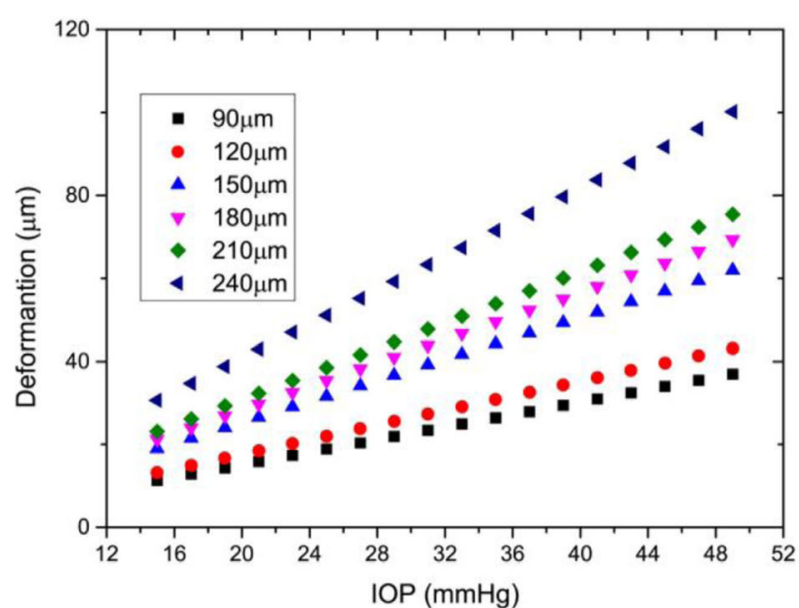

(a)

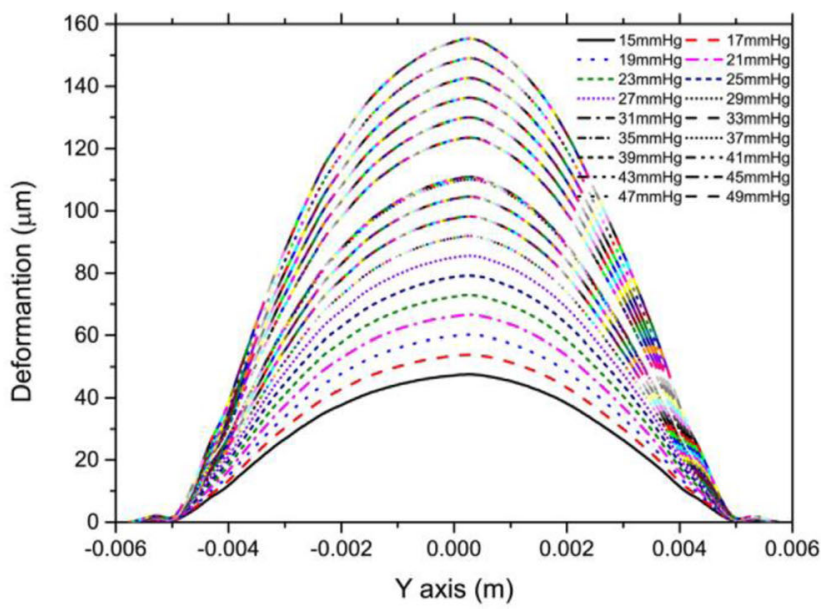

(b)

Fig. 4 a The relationship between corneal vertex displacement and intraocular pressure. The flap thickness was set at 90, 120, 150, 180, 210, and $240 \mu \mathrm{m}$, respectively. The unit of the corneal vertex displacement was $\mu \mathrm{m}$. $\mathbf{b}$ The relationship between displacement of the anterior corneal surface along the $Y$ axis and intraocular pressure. IOP ranged from 15 to $49 \mathrm{mmHg}$

Figure 6 showed the relationship between stress on the anterior and posterior corneal surfaces along the Y-axis. IOP was constant at $17 \mathrm{mmHg}$. The flap thickness was set to $90,120,150,180$, and $210 \mu \mathrm{m}$, respectively.

As seen in Fig. 6(a), stress distribution on the corneal surface was not completely bilaterally symmetrical, but the stress on the corneal surface tended to be at the maximum at the corneal vertex; however, because of the fluctuation in stress distribution, the stress was not at a maximum at the corneal vertex, which might be the result of asymmetrical mesh generation. In fact, the thinnest point of the cornea was not at its center. Meanwhile, the asymmetry of the cornea could result in an asymmetrical distribution of stress. In the center of the cornea, the stress on the anterior corneal surface increased with corneal flap thickness, but the stress on the corneal edge did not significantly change. Moreover, the stress fluctuates slightly if there was no corneal flap. Nevertheless, stress

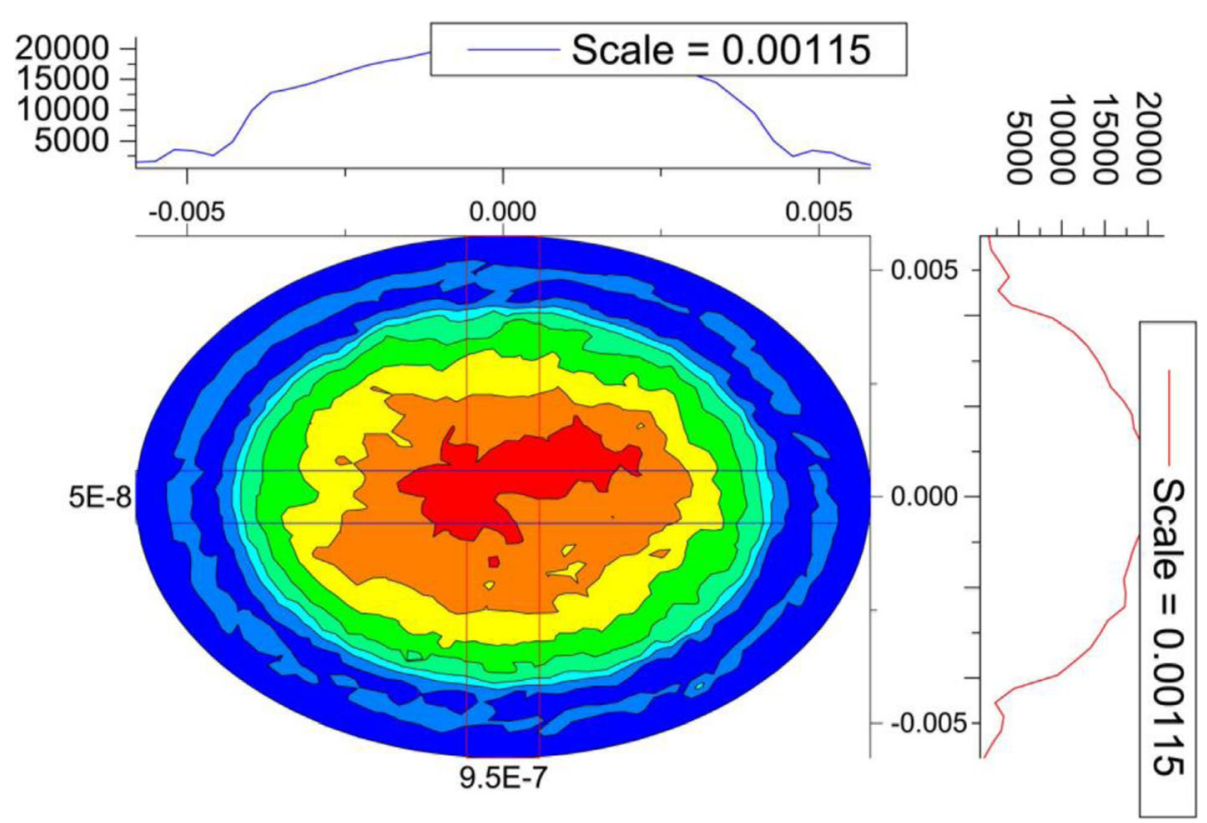

Fig. 5 Contour map of the distribution of stress on the anterior corneal surface. Flap thickness was constant at $120 \mu \mathrm{m}$ and the intraocular pressure was $17 \mathrm{mmHg}$ 


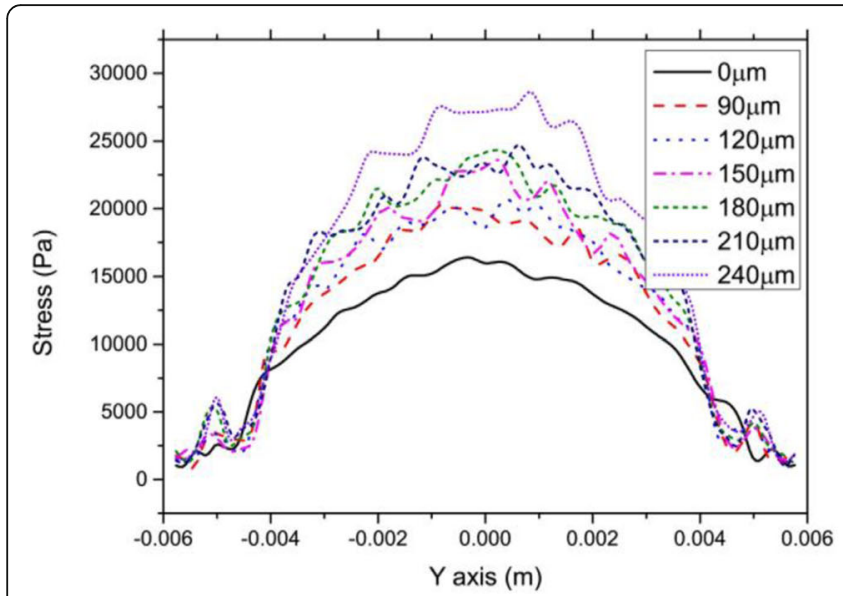

(a)

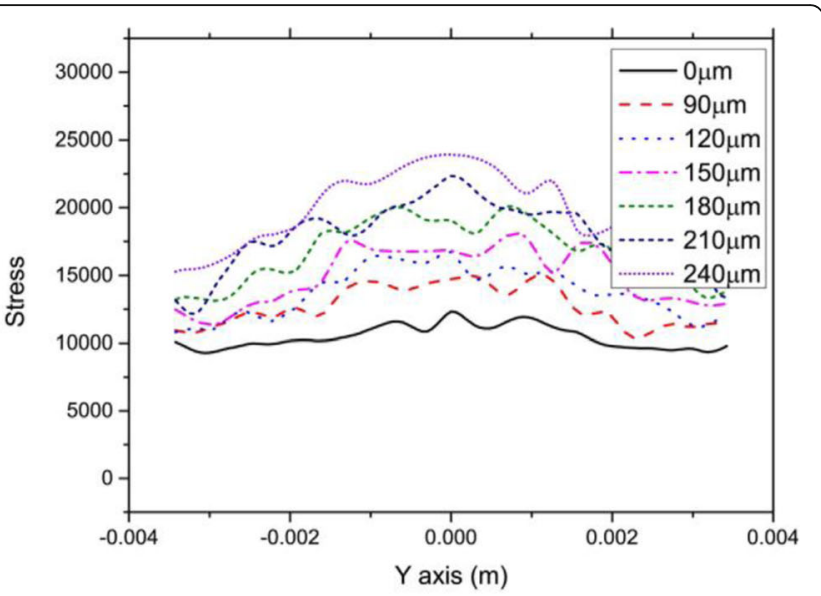

(b)

Fig. 6 Relationship between stress on the anterior and posterior corneal surfaces along the Y-axis and flap thickness. The flap thickness was set to $90,120,150,180,210$, and $240 \mu \mathrm{m}$, respectively. Intraocular pressure was constant at $17 \mathrm{mmHg}$. a Anterior surface. b Posterior surface

fluctuated more significantly with an increase in corneal flap thickness. Finally, stress increased significantly around the incision in the corneal flap. The results indicated that both the incision and thickness of the corneal flap had an obvious effect on stress distribution on the cornea.

As shown in Fig. 6(b), changes in stress on the posterior surface with the $\mathrm{Y}$ value were not more significant than those on the anterior surface. The stress on the interior corneal surface increased with corneal flap thickness, and stress fluctuated more significantly. At the same time, the incision in the corneal flap had nearly no influence on the stress on the posterior corneal surface.

\section{Effect of the IOP on the stress on the corneal surface}

Figure 7 showed the relationship between stress on the anterior and posterior corneal surfaces along the $\mathrm{Y}$-axis and IOP. IOP was set to $15-49 \mathrm{mmHg}$, and the corneal flap thickness was constant at $120 \mu \mathrm{m}$.

As shown in Fig. 7(a), the stress on the center of the anterior corneal surface increased significantly with IOP, but the increase in IOP at the corneal edge had a lesssignificant influence on the stress. In addition, there was nearly no change in stress near the corneal flap with the increase in IOP.

From Fig. 7(b), we observed that stress on the center of the posterior surface increased with IOP, but the increase was much less significant than that of the anterior surface. The stress on the edge of the posterior surface increased with IOP, but the increase was much less significant than that of the center. In addition, there was no sharp change in stress distribution on the incision of the corneal flap.

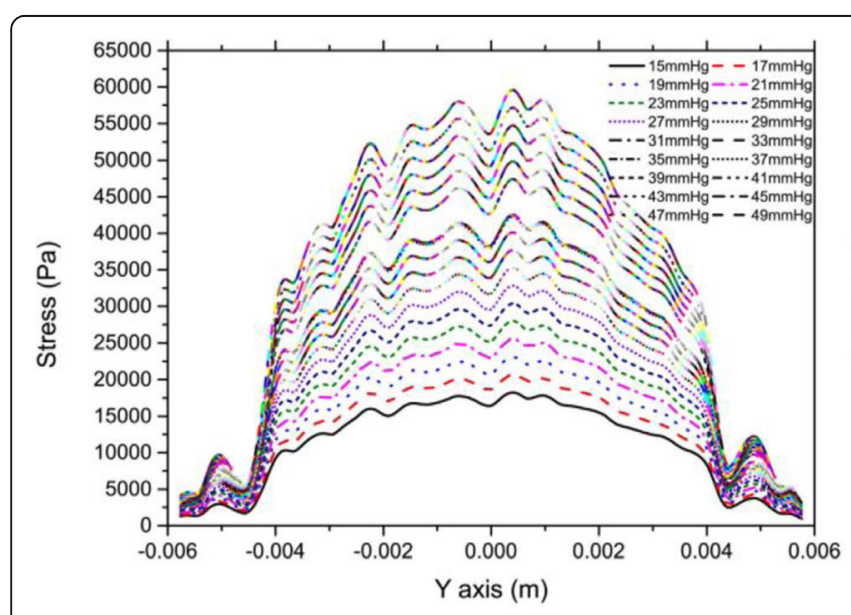

(a)

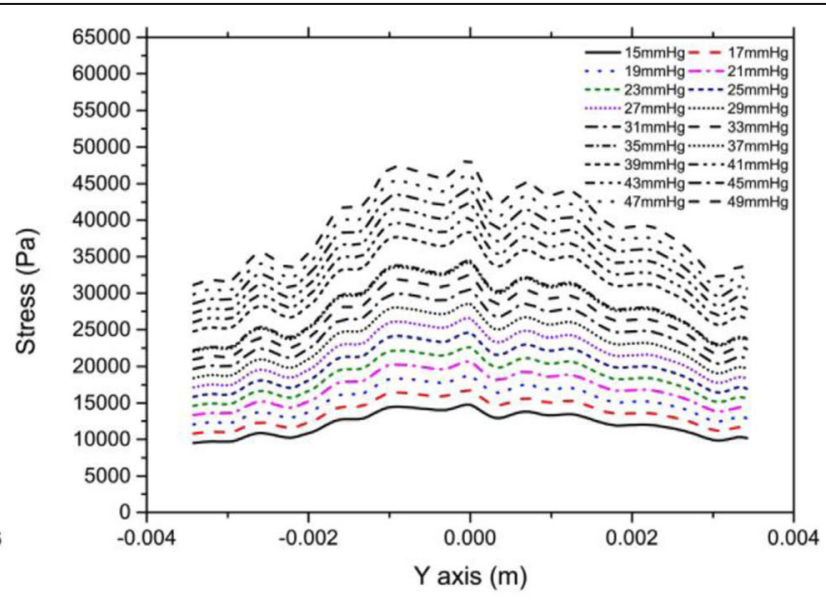

(b)

Fig. 7 Relationship between stress on the anterior and posterior corneal surfaces along the Y-axis and IOP. IOP was set to $15-49 \mathrm{mmHg}$. The corneal flap thickness was constant at $120 \mu \mathrm{m}$. a Anterior surface. b Posterior surface 
Influence of the thickness of corneal flap and IOP on strain on the corneal surface

Figure 8(a) showed the relationship between strain on the anterior corneal surface along the $\mathrm{Y}$-axis and corneal flap thickness. IOP was constant at $17 \mathrm{mmHg}$. Corneal flap thickness was set to $90,120,150,180,210$, and $240 \mu \mathrm{m}$, respectively. Figure 8 (b) showed the relationship between strain on the anterior corneal surface along the $\mathrm{Y}$-axis and IOP. IOP was set to $15-49 \mathrm{mmHg}$, and corneal flap thickness was constant at $120 \mu \mathrm{m}$.

As shown in Fig. 8(a), the strain distribution on the corneal surface was similar to that of the stress distribution. In the center of the cornea, the strain on the anterior corneal surface increased with corneal flap thickness, but there was no significant change in the strain on the corneal edge. It could be seen from Fig. 8(b) that the strain on the center of the anterior corneal surface increased significantly with IOP, but the strain on the corneal edge was less-significantly influenced by IOP. Moreover, there was nearly no change in the strain near the corneal flap with an increase in IOP.

\section{Discussion}

The creation of corneal flaps had a significant impact on the biomechanical properties of the cornea. Corneal hysteresis changes had been investigated using an ocular response analyzer, and the results had shown that thicker flaps presented a greater biomechanical impact on the cornea [18]. Deenadayalu et al. [19] demonstrated that the depth of the lenticular cut was a significant parameter that was tested at varying depths from $0.24 \mathrm{D}$ at $100 \mu \mathrm{m}$ to $1.25 \mathrm{D}$ at $275 \mu \mathrm{m}$; however, in the study, the displacement of the corneal surface and the distribution of stress and strain were explored. The results also indicated a linear relationship between the displacement of the anterior corneal surface and corneal flap thickness. These differences in results could be attributed to a different Young modulus. Medeiros et al. [18] revealed that biomechanical effects might also be important in explaining the changes in the curvature of the residual stroma after flap creation and photoablation that did not represent ectasia but that, nonetheless, had an effect on refractive outcome. Uzbek et al. [20] demonstrated that flap creation with the IntraLase laser produced a biomechanical consequence consistent with reduction in corneal stiffness. One limitation to our study was that the actual corneal cutting depth during corneal refractive surgery was not considered. In fact, the actual ablation profile was related to the refractive surgery procedure. The refractive surgery procedures included conventional refractive surgery, wave-front aberrationguided surgery, SMILE (small-incision lenticule extraction) surgery and so on. In this study, only the effect of the corneal flap on biomechanics was considered. Another limitation of the study was that flap hinge was not taken into account. Actually the position and size of the flap hinge had influence on the result of refractive surgery. In addition, the result of obvious non-rotational symmetry would be shown due to the existence of flap hinges. The effect of different refractive surgery procedures and the position and size of the flap hinge on corneal biomechanics would be studied in the future.

In addition, displacement of the anterior corneal surface included displacement along the $\mathrm{X}$-, $\mathrm{Y}$-, and $\mathrm{Z}$-axes. The analysis revealed that the displacement along the Zaxis was dominant $(\sim>90 \%)$; therefore, displacement of

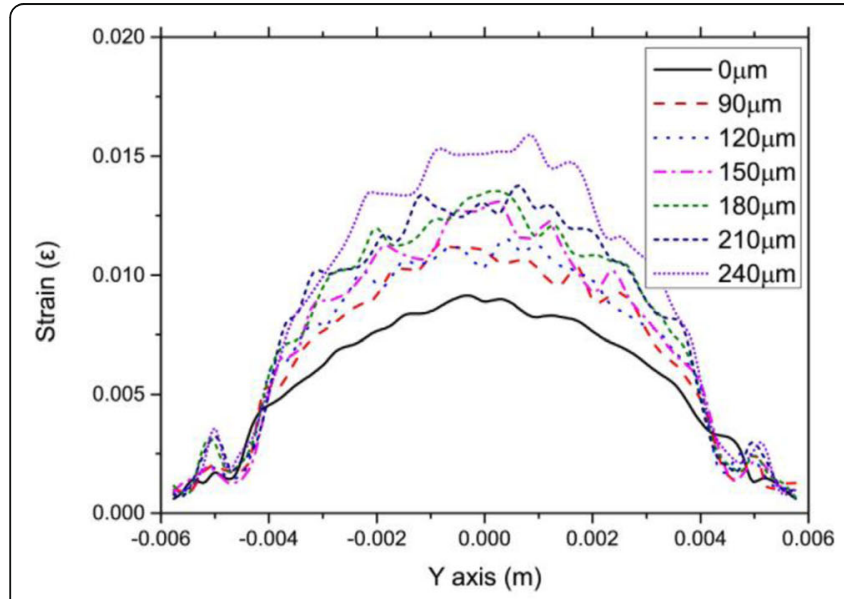

(a)

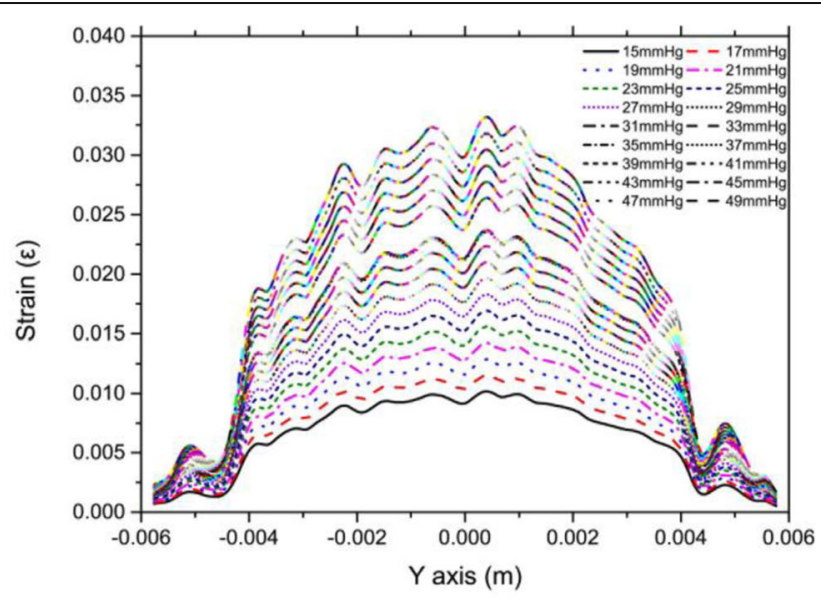

(b)

Fig. 8 a Relationship between the strain on the anterior corneal surface along the $Y$-axis and corneal flap thickness. The corneal flap thickness was set to 90,120, 150, 180, 210, and $240 \mu \mathrm{m}$, respectively. The intraocular pressure (IOP) was constant at $17 \mathrm{mmHg}$. b Relationship between strain on the anterior corneal surface along the Y-axis and corneal flap thickness. IOP was set to $15-49 \mathrm{mmHg}$. Corneal flap thickness was constant at $120 \mu \mathrm{m}$ 
the anterior corneal surface along the $\mathrm{Z}$-axis was considered.

Our study indicated that stress distribution did not cause an obvious rotational symmetry, but fluctuated significantly, even near the corneal vertex. This could be because stress on the surface units must be different from that on the interior units, while stress on the anterior and posterior corneal surfaces was discussed. Meanwhile, mesh generation and mesh asymmetry also affected stress distribution on each mesh unit. In addition, stress on the corneal flap incision did not significantly increased, while an increase in stress on the corneal edge might be caused by the fixed and restrained corneal under surface. Finally, the creation of corneal flaps could significantly increase stress on the cornea. For example, when IOP was $17 \mathrm{mmHg}$ and the flap was $120 \mu \mathrm{m}$ thick, the maximum stress was $20,678 \mathrm{~Pa}$, while it was $16,398 \mathrm{~Pa}$ before the creation of the corneal flap, an increase of $26.1 \%$. In addition, when IOP was 49 $\mathrm{mmHg}$ and the flap was $120 \mu \mathrm{m}$ thick, the maximum stress was $59,603 \mathrm{~Pa}$, while it was $47,265 \mathrm{~Pa}$ before the creation of the corneal flap, an increase of $26.1 \%$ also. The significant increase in stress remarkably influenced the subsequent corneal shape.

Although the biomechanical mechanisms for creating the flap in LASIK refractive surgery had been studied, FEM relied strongly on the mechanical properties that were assigned to the corneal tissue and some assumptions within the model. A better understanding of the biomechanical response of the cornea should be provided by a sophisticated corneal biomechanical model, including different cutting depths and optical zone sizes; therefore, a more accurate prediction of the post-surgery results would be available.

Our results showed that IOP had distinctly influence on the corneal vertex displacement, the distribution of stress and the distribution of strain. In particular, the corneal vertex displacement and the distribution of stress on the center of the corneal surface increased significantly with IOP, but those at the corneal edge changed less-significant significantly. This might be an important source of the instability in the results of refractive surgery.

In this study, the biomechanical effects after creating the flap resulted in a hyperopic shift. In fact, for the clinical refractive surgery system, the main goal is to correct the refractive error. Therefore, the residual refractive error was small in most clinical measurements [21, 22]. Hondur et al. found that more than $90 \%$ of eyes were within $\pm 0.50 \mathrm{D}$ of emmetropia in 12 months [22]. But individual residual refractive error may be $\pm 1 \mathrm{D}$ or more. This may be partly due to the effects of biomechanics.

Furthermore, the distribution of strength throughout the cornea may play an important role. However, as far as I know, there were no the clinical measurements for the distribution of strength. Additionally, the distribution was particularly useful for the analyses of individual human eye. Once the distribution was measured in vivo in clinical, the influence of the distribution on biomechanics could be analyzed.

\section{Conclusion}

The corneal flap could obviously cause a deformation of the anterior corneal surface. For example, the displacement of the corneal vertex was $15 \mu \mathrm{m}$ more than that without the corneal flap when the corneal flap was $120 \mu \mathrm{m}$ thick. The issue of cutting depth in refractive surgery was not considered in our study and would be explored in the future. This displacement was enough to cause aberrations in the human eye. With a finite flap thickness, the displacement of the anterior corneal surface increased linearly with IOP. In the central part of the cornea, the stress on the anterior corneal surface increased with flap thickness, but there was no significant change in the stress on the corneal edge. The change in the stress on the posterior corneal surface was significantly less than that on the anterior surface. There was a significant increase in the stress around the incision in the corneal flap. In addition, the stress in the central part of the anterior corneal surface increased significantly as IOP increased, but the IOP increase had a clearly less effect on stress distribution at the edge of the cornea. Distributions of strain on the corneal surface were similar to those of stress; therefore, the changes in the biomechanical properties of the cornea after refractive surgery could not be ignored.

\section{Abbreviations}

CCT: central thinnest corneal thickness; CFD: computational fluid dynamics; FEM: finite element model; IOP: intra-ocular pressure

\section{Acknowledgements}

Not applicable.

Authors' contributions

LF coordinates the overall work of the paper, the writing of the paper, was a major contributor in the manuscript. YW designs the scheme of this paper, RY and SD performs software simulation for the model, JD and LW analyzes the data required in the paper. All authors read and approved the final manuscript.

\section{Funding}

This study was supported in part by grants from Natural Science Foundation of Jiangxi Province (20192BAB207035). The fund played an important role in design of the study, the collection and analysis of data.

Availability of data and materials

All data generated or analyzed during this study are included in this published article.

Ethics approval and consent to participate

Not applicable.

Consent for publication

Not applicable. 


\section{Competing interests}

The authors declare that they have no competing interests.

\section{Author details}

${ }^{1}$ Key Laboratory of National Engineering Laboratory for Nondestructive Testing and Optoelectric Sensing Technology and Application (Ministry of Education), Nanchang Hangkong University, Add: No 696. Fenghenan Rd, Donghu District, Nanchang city, Jiangxi Province, 330063, China. ${ }^{2}$ Tianjin Eye Hospital \& Eye Institute, Ophthalmology and Visual Development Key Laboratory, Tianjin Medical University, Tianjin 300020, China.

Received: 20 November 2019 Accepted: 7 February 2020 Published online: 24 February 2020

\section{References}

1. Reinstein DZ, Archer TJ, Gobbe M. The history of LASIK. J Refract Surg. 2012; 28:291-8.

2. Binder PS. Analysis of ectasia after laser in situ keratomileusis: risk factors. J Cataract Refract Surg. 2007;33:1530-8.

3. Santhiago MR, Giacomin NT, Smadja D, Bechara SJ. Ectasia risk factors in refractive surgery. Clin Ophthalmol. 2016;10:713-20.

4. Wu W, Wang Y. Corneal higher-order aberrations of the anterior surface, posterior surface, and Total cornea after SMILE, FS-LASIK, and FLEx surgeries. Eye Contact Lens. 2016;42:358-65.

5. Randleman JB, Su JP, Scarcelli G. Biomechanical changes after LASIK flap creation combined with rapid cross-linking measured with Brillouin microscopy. J Refract Surg. 2017;33:408-14.

6. Studer HP, Riedwyl H, Amstutz CA, Hanson JV, Buchler P. Patient-specific finite-element simulation of the human cornea: a clinical validation study on cataract surgery. J Biomech. 2013;46:751-8.

7. Srodka W. Evaluating the material parameters of the human cornea in a numerical model. Acta Bioeng Biomech. 2011;13:77-85.

8. Oliveira CM, Ferreira A, Franco S. Wavefront analysis and Zernike polynomial decomposition for evaluation of corneal optical quality. J Cataract Refract Surg. 2012;38:343-56.

9. Liang J, Grimm B, Goelz S, Bille JF. Objective measurement of wave aberrations of the human eye with the use of a Hartmann-shack wave-front sensor. J Opt Soc Am A Opt Image Sci Vis. 1994;11:1949-57.

10. Uchio E, Ohno S, Kudoh J, Aoki K, Kisielewicz LT. Simulation model of an eyeball based on finite element analysis on a supercomputer. $\mathrm{Br} J$ Ophthalmol. 1999;83:1106-11.

11. Elsheikh A. Finite element modeling of corneal biomechanical behavior. J Refract Surg. 2010;26:289-300.

12. Truffer O, Abler D, Pajic B, Grabner G, Kraker H, Buchler P. Optimization of surgical parameters based on patient-specific models: application to arcuate keratotomy. J Cataract Refract Surg. 2019;45:1084-91.

13. Whitford C, Studer H, Boote C, Meek KM, Elsheikh A. Biomechanical model of the human cornea: considering shear stiffness and regional variation of collagen anisotropy and density. J Mech Behav Biomed Mater. 2015:42:76-87.

14. Yu JG, Bao FJ, Feng YF, Whitford C, Ye T, Huang YB, Wang QM, Elsheikh A. Assessment of corneal biomechanical behavior under posterior and anterior pressure. J Refract Surg. 2013;29:64-70.

15. Xiang $Y$, Shen $M, X u e ~ C, W u ~ D$, Wang $Y$. Tensile biomechanical properties and constitutive parameters of human corneal stroma extracted by SMILE procedure. J Mech Behav Biomed Mater. 2018;85:102-8.

16. Crouch JR, Merriam JC, Crouch ER, Khandji A. Finite element analysis applied to cornea modeling and tissue deformation. Invest Ophth Vis Sci. 2004;45:U162

17. Guilbert E, Saad A, Grise-Dulac A, Gatinel D. Corneal thickness, curvature, and elevation readings in normal corneas: combined Placido-Scheimpflug system versus combined Placido-scanning-slit system. J Cataract Refract Surg. 2012;38:1198-206.

18. Medeiros FW, Sinha-Roy A, Alves MR, Dupps WJ Jr. Biomechanical corneal changes induced by different flap thickness created by femtosecond laser. Clinics (Sao Paulo). 2011;66:1067-71

19. Deenadayalu C, Mobasher B, Rajan SD, Hall GW. Refractive change induced by the LASIK flap in a biomechanical finite element model. J Refract Surg. 2006;22:286-92.

20. Uzbek AK, Kamburoglu G, Mahmoud AM, Roberts CJ. Change in biomechanical parameters after flap creation using the Intralase femtosecond laser and subsequent excimer laser ablation. Curr Eye Res. 2011;36:614-9.

21. Arba-Mosquera S, de Ortueta D. Analysis of optimized profiles for 'aberration-free' refractive surgery. Ophthalmic Physiol Opt. 2009:29:535-48.

22. Hondur AM, Akcam HT, Karaca EE, Yazici Eroglu H, Aydin B. Autologous serum eye drops accelerate epithelial healing after LASEK. Curr Eye Res. 2016:41:15-9.

\section{Publisher's Note}

Springer Nature remains neutral with regard to jurisdictional claims in published maps and institutional affiliations.
Ready to submit your research? Choose BMC and benefit from:

- fast, convenient online submission

- thorough peer review by experienced researchers in your field

- rapid publication on acceptance

- support for research data, including large and complex data types

- gold Open Access which fosters wider collaboration and increased citations

- maximum visibility for your research: over $100 \mathrm{M}$ website views per year

At $\mathrm{BMC}$, research is always in progress.

Learn more biomedcentral.com/submissions 